\title{
Economía y naturaleza humana, volviendo a Smith y Marx
}

\author{
Federico Aguilera Klink \\ Universidad de La Laguna, Tenerife, España. \\ Email: faguiler@ull.edu.es
}

\begin{abstract}
Resumen: Trato de mostrar que la noción de naturaleza humana con la que trabaja la economía académica neoclásica o convencional, que se enseña habitualmente como ciencia económica, tiene muy poco que ver con la esencia real de la naturaleza humana, tal y como vamos conociendo cada vez mejor. La paradoja, tan interesante como relevante, es que pensadores como Smith y Marx sí entendieron y expresaron con más claridad esa naturaleza humana puesto que estaban realmente interesados en conocerla en lugar de adoctrinarnos con hipotéticos comportamientos atribuibles a ella.
\end{abstract}

Palabras clave: Naturaleza humana; economía; racionalidad económica; comportamiento humano.

\section{Economics and human nature, returning to Smith and Marx}

\begin{abstract}
I intend to show that the notion of human nature underlying in academic neoclassical or conventional economics, usually taught as economic science, has hardly nothing to do with real essential human nature, as far as we are better knowing it. An interesting and relevant paradox is emerging in the sense that thinkers like Smith and Marx were able of understanding and presenting very clearly human nature because they were really interested in knowing about human being instead of indoctrinate us about supposed behaviors attributable to the said nature.
\end{abstract} behavior.

Key words: Human nature, economics, economic rationality, human

\section{Economia e natureza humana, voltando para Smith e Marx}

Resumo: No artigo tento mostrar que a noção de natureza humana com a qual trabalha a economia acadêmica neoclássica ou convencional, que normalmente ensina-se como ciência econômica, tem muito pouco a ver com a verdadeira essência do ser humano, tal como nós a conhecemos atualmente. O paradoxo, tão interessante como relevante, é que pensadores como Smith e Marx entenderam e expressaram de forma mais clara essa natureza humana uma vez que eles estavam realmente interessados em conhecê-la em vez de doutrinar-nos com hipotéticos comportamentos a ela imputáveis.

Palavras-chave: Natureza humana; economia; racionalidade econômica; comportamento humano. 
“Conocía a su gente. Sabía cuánto tardan en oír algo distinto por haber estado sometidos secularmente al machaqueo del mismo martillo”. José Luis Sampedro, 1961. El río que nos lleva.

Los estudiosos del derecho, la economía y la política carecen de herramientas para contemplar su propia sociedad con objetividad. Raramente consultan el amplio conocimiento del comportamiento humano acumulado por la antropología, la psicología, la biología o la neurología. Somos animales altamente cooperativos, sensibles a la injusticia, a veces beligerantes y principalmente amantes de la paz. F. De Waal, 2011. La edad de la empatía.

\section{De la economía disociada a la economía integrada}

Los economistas hemos recibido una enseñanza de la economía que nos lleva a no poder relacionar ni comprender adecuadamente las cuestiones que tratamos de estudiar. Hemos aprendido (más bien hemos sido adoctrinados en) una idea de la "naturaleza humana”, en el sentido de que "somos egoístas por naturaleza”, que conduce "naturalmente” a una idea de racionalidad económica y del hombre centrada en la maximización de los beneficios. En otras palabras, considera al hombre como si sólo fuera un agente racional, entendiendo por racional el que sigue un comportamiento maximizador sin sentimientos ni valores morales que, además, ignora las relaciones con el medio ambiente y se olvida de que dependemos de él. De hecho el medio ambiente desaparece de nuestras estructuras mentales y emocionales gracias al aprendizaje recibido pues aprendemos a no ver lo que tenemos delante ni aquello que es vital para poder vivir como seres humanos. Hemos perdido la conciencia de nuestra dependencia de la naturaleza y de que somos naturaleza, en definitiva, hemos perdido (nos han enseñado a perder) la conciencia de nosotros mismos y no nos hemos enterado.

“Todos los tramperos disimulan sus trampas (...) Entre los humanos, las trampas se camuflan presentándolas como leyes de la naturaleza. Como por ejemplo la afirmación de que <el ser humano es egoísta>, y lo es desde los genes hasta la moral. Una teoría económica ha convertido esta tesis, con el apoyo de las modernas máquinas de cómputo, en una nueva ley natural” (Schirrmacher 2014: 9-10).

Por otro lado se separa lo público de lo privado y lo individual de lo colectivo, como si esta separación fuese real y beneficiosa, mientras que el mercado libre se presenta como si fuera algo opuesto a la aplicación de reglas, es decir, como si la libertad fuera ajena a las reglas, que se suelen calificar de "intervención no deseable" excepto cuando esas reglas benefician al capital, es decir, a los poderosos. 
Para dar 'legitimidad' a este tipo de enseñanzas se nombra como responsable de este tipo de pensamiento a autores como Adam Smith, al que los estudiantes apenas leen (y los profesores tampoco), pues "todo lo que hay que aprender está en los Manuales” que transforman la economía en una serie de ejercicios cuyo dominio permite aprobar los cursos a la vez que hace creer que se está aprendiendo realmente economía. Se confunde aprobar y repetir "ideas” con aprender a pensar por cuenta propia.

Mi intención es mostrar, de manera resumida, que en los textos de autores como Smith y Marx hay, fundamentalmente, una llamada muy clara a que la economía sea protagonizada por seres humanos, es decir, a la humanización de la economía, a que esté al servicio del hombre (y de la comunidad), entendiendo al hombre como un ser que siente y cuyo objetivo no es, principalmente, la mejora material sino su crecimiento humano, su vinculación con él mismo, con los demás y con la naturaleza.

Necesitamos poner en práctica lo que sugería Mishan hace más de sesenta años al señalar que "Las propuestas detalladas resultan secundarias con respecto a lo que yo juzgo que debe ser la principal tarea: convencer a la gente de la necesidad de un cambio radical en la manera habitual de observar los acontecimientos económicos” (Mishan 1971: 11). Se trata de trabajar hacia el objetivo de la integración frente a la situación actual de completa disociación, como muestra el Cuadro 1, para evitar que "pensar como un economista vaya en contra de la comunidad”, como reza el subtítulo del libro de Marglin, The dismal science (2008). El futuro de la economía integrada y no disociada, al servicio de las personas consiste en que pensar como un economista vaya a favor de los seres humanos y de la comunidad, lo contrario es lo que estamos viviendo actualmente, basado en la violencia, y sólo nos lleva a más violencia y más sufrimiento en la mayoría de los países y para la mayoría de las personas.

\section{Cuadro 1}

\section{LAECONOMÍASEPARADA-DISOCIADA}

\begin{tabular}{|l|l|}
\hline $\begin{array}{l}\text { ECONOMIAMAXIMIZADORADE VALO- } \\
\text { RES MONETARIOS Y MINIMIZADORA } \\
\text { DE COSTES. PIB }\end{array}$ & ETICA, SENTIMIENTOS, VALORES \\
\hline $\begin{array}{l}\text { ECONOMIA (SEPARADA DEL MEDIO } \\
\text { AMBIENTE) }\end{array}$ & NATURALEZA \\
\hline $\begin{array}{l}\text { AGENTE RACIONAL } \\
\text { (CONSUMIDOR, EMPRESARIO) }\end{array}$ & SER HUMANO \\
\hline $\begin{array}{l}\text { EL MERCADO “LIBRE Y } \\
\text { AUTORREULADO” }\end{array}$ & $\begin{array}{l}\text { REGLAS DE JUEGO, MARCO } \\
\text { INSTITUCIONAL, PODER }\end{array}$ \\
\hline $\begin{array}{l}\text { “NOSOTROS” } \\
\text { INTERDEPENDENCIAS CAUSALES EN- } \\
\text { TRE PAISES) }\end{array}$ & $\begin{array}{l}\text { "ELLOS” } \\
\text { ECONOMIA COMO SISTEMA CERRADO } \\
\text { ECONOMIA COMO SISTEMA ABIERTO }\end{array}$ \\
\hline
\end{tabular}


Las advertencias para salirnos de esta economía disociada que ignora y empobrece al ser humano, tanto desde el punto de vista intelectual como psíquico, además de empobrecer materialmente a la mayoría, no son nuevas pero han sido sistemáticamente ignoradas y, cuando esto no era posible, se descalificaban. Quizás sea Morin uno de los autores que de manera más clara ha expresado el problema de la disociación. "La economía, la ciencia social más avanzada matemáticamente, es la más retrasada social y humanamente, pues se abstrae de las condiciones sociales, históricas, políticas, psicológicas y ecológicas que son inseparables de las actividades económicas...La inteligencia parcelada destruye en embrión toda posibilidad de comprensión y reflexión. Incapaz de enfocar el contexto y el complejo planetario, la inteligencia ciega se vuelve inconsciente e irresponsable. Se ha vuelto mortífera”. (Morin 1993: 67). De ahí la hipotética y disparatada pretensión de esta economía disociada de creer que ofrece una "racionalidad universal”.

Sin embargo, desde dentro de la economía las críticas son muy importantes también. Para no repetirme, remito al lector a Aguilera (2010 y 2013). La idea de deshumanización no abarca sólo el contenido de lo que se estudia sino también la influencia en la actitud psicológica de los estudiantes que acaban por "jugar" a creer que han aprendido. En este sentido, las pinceladas psicológicas sobre los estudiantes, fruto de su propia observación, son muy relevantes pues todo estudiante necesita creer que el esfuerzo dedicado a estudiar-aprender-aprobar unas materias y unas lógicas tiene que servir para algo, aunque sólo sea para salir de la universidad y/o convertirse en profesor sin preguntarse qué significan esas lógicas y así perpetuar el sistema de desviar la atención. Pero las quejas siguen siendo importantes y desatendidas, tal y como ocurre con la reflexión más reciente de Morin (2001) sobre la necesidad de aplicar el “diezmo epistemológico” en la Universidad, es decir, de dedicar el 10 por 100 del presupuesto a preguntarse ¿Qué estamos haciendo en la Universidad?

Galbraith, en lo que algunos consideran como su "testamento económico”, retoma y amplía algunas de las ideas sobre las que ya había escrito anteriormente para presentar un diagnóstico lúcido y contundente sobre la economía que se enseña y sobre cómo se nos enseña a todos a no ver que la economía es un 'fraude', inocente, en el sentido de que “...quienes participan en él no lo reconocen explícitamente como tal (...) Una parte de este fraude es consecuencia de la economía tradicional y la manera en que ésta se enseña, otra tiene su origen en concepciones rituales de la vida económica. Estas últimas pueden apoyar con claridad intereses individuales y colectivos y, en particular, como cabría esperar, los de los miembros más afortunados, mejor relacionados y políticamente destacados de la comunidad, y pueden adquirir la respetabilidad y la autoridad del conocimiento cotidiano. De esta forma, determinado punto de vista sobre la vida económica no aparece como creación de un individuo o de un grupo en particular sino como algo natural e incluso justo.” (Galbraith 2004: 13-14), pero sigue siendo un fraude. 
Hablar de sistema de mercado en lugar de capitalismo “...carece de sentido; es una fórmula errónea, insípida, complaciente (...) Hoy se cree que las empresas y los capitalistas particulares carecen de poder; y el hecho de que el mercado esté sujeto a una dirección corporativa hábil y completa ni siquiera se menciona en la mayor parte de los cursos de economía. En esto reside el fraude.” (Ibid: 24-25). (La negrita es mía). Hay muchos más fraudes que Galbraith va desgranando capítulo tras capítulo y que se siguen enseñando como algo científico.

Estas críticas son sistemáticamente ignoradas y se sigue manteniendo, en esencia, el mismo núcleo teórico de la enseñanza de la licenciatura y de posgrado. Este comportamiento, consistente en negar la evidencia empírica manteniendo sin cambiar la misma teoría, ha sido considerado como un comportamiento delirante, “...los "economistas” han producido un discurso propio que "explica” lo que sucede en unos términos idiosincrásicos y tiene la característica peculiar de no modificarse aunque sus predicciones no se cumplan o los hechos parezcan desmentirlo. Los profesionales de la salud mental trabajamos con personas que mantienen discursos con características semejantes”, (Fernández Liria 2013: 140), y es importante no perder de vista que ese comportamiento se enseña como actitud y como lógica habitual en las Facultades de economía de todo el mundo, es decir, es legitimado como si fuera algo científico por la propia Universidad.

Leontief (1982) hace un diagnóstico que muestra muy acertadamente tres de los principales problemas que sigue manteniendo la economía académica y que son a) Su aislamiento de las demás disciplinas, su separación, podemos decir, b) Su insistencia en la obediencia o en la sumisión como método y c) Su irrelevancia. La combinación del aislamiento, la sumisión y la irrelevancia es totalmente empobrecedora para el estudiante, tanto desde el punto de vista intelectual como desde el punto de vista psíquico, pues lo enajena de la realidad y de sí mismo, es decir, lo deshumaniza. La realidad es que esa obediencia, ese aislamiento y ese comportamiento delirante han ido llevando a la economía académica a enajenarse cada vez más, es decir, a separarse o disociarse del ser humano, de la ética, de los sentimientos y de los valores, de la naturaleza, del mercado como construcción humana sometida a reglas, del poder, del "nosotros" como si nuestro estilo de vida fuera independiente del estilo de vida de otras personas y países ("ellos") y, en definitiva, del objeto que, supuestamente, pretende estudiar y comprender. "La memoria del norte se divorcia de la memoria del sur. La acumulación se desvincula del vaciamiento. La opulencia no tiene nada que ver con el despojo. La memoria rota nos hace creer que la riqueza es inocente de la pobreza, que vienen de la eternidad y que así son las cosas” (Galeano 1998: 35).

Es lo que Erich Fromm (1994) califica como la "patología de la normalidad”, en el sentido de que nos acostumbramos a ver y convivir con una realidad enferma, patológica y, además, la justificamos y nos adaptamos a ella pero, al mismo tiempo, estamos esencialmente disociados de ella pues no "vemos" con claridad qué es lo que está ocurriendo, como muy bien 
expresa Galeano, e incluso negamos que nosotros nos comportemos de manera deshumanizada. La razón, o al menos una de ellas, consiste en que es el propio capitalismo el que necesita un tipo determinado de 'hombre enajenado’ para poder funcionar pero esa misma enajenación nos impide vernos a nosotros como seres enajenados. El Roto tiene un dibujo en el que una madre, con un hijo pequeño sentado en su regazo, miran hacia el horizonte mientras ella le dice "Para comprender a los adultos tendrás que esperar a hacerte mayor y perder el juicio”. Y eso es exactamente lo que parece ocurrir. Quiero decir que con frecuencia criticamos al capitalismo y a otros "ismos" pero dejando de lado que todo sistema necesita de personas que actúen y se comporten de determinada manera para funcionar y que somos las personas las que, consciente o inconscientemente, lo hacemos funcionar, por miedo, por convencimiento, por adoctrinamiento o porque no sabemos hacer otra cosa. Esto es lo que Kapp (1968) entiende por "hábitos de pensamiento institucionalizados”, pero lamentablemente, para la mayoría de los institucionalistas, las instituciones a las que prestan habitualmente atención, siguen siendo las reglas de juego y el poder pero no las instituciones consideradas, también, como hábitos de pensamiento y de comportamiento que son las que nos pueden permitir o impedir (adoctrinamiento) hacernos las preguntas relevantes y empezar a pensar con claridad y libertad. "Ningún hombre mira jamás el mundo con ojos prístinos. Lo ve a través de un definido equipo de costumbres e instituciones y modo de pensar (...) La historia de la vida del individuo es ante todo y sobre todo una acomodación a las normas y pautas tradicionalmente transmitidas por la comunidad (...) La uniformidad de la costumbre, de la perspectiva que ve extenderse a su alrededor, le parece bastante convincente, y en verdad esconde ante él un accidente histórico. Acepta sin mayor dificultad la equivalencia entre la naturaleza humana y sus propias modalidades culturales” (Benedict 1967: 9-18).

Dentro de este adoctrinamiento, destaca el egoísmo entendido como algo consustancial a la naturaleza humana y repetido hasta la saciedad mediante el aforismo según el cual “el hombre es lobo para el hombre”, algo que es falso puesto que el lobo es el animal más cooperativo, la idea se sigue repitiendo como si fuera verdad, nos la creemos y la hacemos nuestra aunque nuestro comportamiento habitual no sea así. "Este proverbio romano resume la visión asocial que continúa inspirando al derecho, a la economía y a las ciencias políticas...Ser egoísta es inevitable y necesario, pero sólo hasta cierto punto... somos el producto de fuerzas opuestas, como la doble necesidad de velar por los intereses opuestos y la de congeniar”. (De Waal 2007: 234). El resultado de esta visión asocial, que se enseña como si fuera científica y acorde con la naturaleza humana y que se legitima en las universidades es el disparate más absoluto. Además, resulta que la realidad nos demuestra lo contrario, a saber, que "Los Homo sapiens están adaptados para actuar y pensar cooperativamente. A partir del primer año de vida los niños ya muestran inclinación por cooperar, no aprenden esa actitud de los adultos: es algo que les nace”. (Tomasello 2010: 24).

¿Por qué no continuamos con esa inclinación innata? Porque la educación que recibimos nos la 'desactiva', consciente o inconscientemente, 
adoctrinándonos con esquemas de competencia o de lucha. Esto es lo que sugiere Damasio “...los seres humanos poseen mecanismos innatos...que son la base probable de algunas estructuras éticas. Sin embargo, las convenciones sociales y las estructuras éticas más complicadas por las que vivimos han de haber surgido culturalmente y haberse transmitido de la misma manera”. (Damasio 2006: 298). Y al haber sido “aprendidas” parecen tener más legitimidad que las estructuras innatas a pesar de que sintamos que no somos como nos hacen creer que somos. Nos enajenan de nosotros mismos, nos alejan de nosotros y nos hacen desconfiar y dudar de nuestras percepciones genuínas.

Y sin embargo, siguiendo a De Waal vemos que, "La condición natural de nuestro linaje es de vinculación y apoyo....Las explicaciones de los orígenes humanos que no tienen en cuenta esta profunda conexión y nos presentan como solitarios que se reunieron de mala gana ignoran la evolución primate (...) No siempre actuamos como los economistas piensan que deberíamos...porque somos menos egoístas y menos racionales de lo que los economistas suponen que somos. Los economistas están siendo adoctrinados en una maqueta de la naturaleza humana que dan por buena hasta tal punto que su propio comportamiento ha comenzado a parecerse a ella. Los mamíferos sociales, en cambio, conocen la confianza, la lealtad y la solidaridad (...) los chimpancés no dejan atrás al desafortunado. Además, tienen maneras de tratar a los aprovechados, como rehusar la cooperación con aquellos que no cooperan. La reciprocidad les permite construir la clase de sistema de apoyo social que muchos economistas ven como una quimera (...) Estamos tan atados a una psicología humana conformada por millones de años de vida en comunidades pequeñas, que de algún modo necesitamos estructurar el mundo que nos rodea de una manera reconocible para dicha psicología. Si pudiéramos conseguir ver a la gente de otros continentes como parte de nosotros e integrarla en nuestro círculo de reciprocidad y empatía, estaríamos construyendo sobre nuestra naturaleza y no yendo contra ella” (DeWaal 2007: 233247). (La negrita es mía). Algo en lo que coincide con lo planteado por Galeano más arriba.

El problema es que las Facultades de economía insisten en enseñar una perspectiva más centrada en el juego que dan de sí las matemáticas que en comprender la economía real. "Me aventuré en ir más allá de las matemáticas y pregunté a mis estudiantes cuestiones cuyo objetivo era expresar cómo iban ellos absorbiendo la economía que subyacía en las matemáticas...Me dí cuenta de que para esos estudiantes la economía era sólo parte del juego de los estudios de licenciatura: aquellos que lo jugaban bien se aseguraban trabajo y sustento mientras que los que lo jugaban mal se dedicarían a ser taxistas. Hacerlo bien significa dominar el formalismo matemático no necesariamente comprender la economía” (Marglin 2008: xiii). En esa situación seguimos, con algunas voces críticas, pero sin llegar a expresar con claridad, por parte de los economistas, que " $<$ De la $<$ ciencia de la economía política, tenemos que decir que, por lo general, es la aplicación hábil, exacta y tecnológica de una teoría totalmente falsa de las necesi- 
dades y valores humanos, una teoría que sólo reconoce la existencia de las necesidades inferiores o materiales” (Maslow 1982: 381).

\section{Algunos aspectos de la dimensión humana de Adam Smith}

\section{El hombre, un ser egoísta y compasivo}

Frente al cliché-hábito de pensamiento que afirma que Smith defendía el egoísmo cómo motivo fundamental del comportamiento humano, considero que es importante destacar algunos párrafos de su "Teoría de los sentimientos morales", publicada originalmente en 1759 ya que permiten cuestionar esa supuesta racionalidad económica individual basada en el egoísmo que tampoco es tan evidente en "La riqueza de las naciones". Sen y Galbraith, entre otros, ya destacaron la necesidad de leer a Smith para evitar malinterpretaciones y tergiversaciones, además de para disfrutar, pero esto sigue sin aplicarse. Un trabajo espléndido sobre el pensamiento de Smith es el de Casassas (2010).

"Por más egoísta que se pueda suponer al hombre, existen evidentemente en su naturaleza algunos principios que le hacen interesarse por la suerte de otros, y hacen que la felicidad de éstos le resulte necesaria, aunque no derive de ella nada más que el placer de contemplarla. Tal es el caso de la lástima o la compasión, la emoción que sentimos ante la desgracia ajena cuando la vemos o cuando nos la hacen concebir de forma muy vívida (...) este sentimiento (...) no se halla en absoluto circunscrito a las personas más virtuosas y humanitarias (...) no se halla desprovisto de él totalmente ni el mayor malhechor ni el más brutal violador de las leyes de la sociedad (...) Como carecemos de la experiencia inmediata de lo que sienten las otras personas, no podemos hacernos ninguna idea de la manera en que se ven afectadas, salvo que pensemos cómo nos sentiríamos nosotros en su misma situación” (...) nos vemos afectados por lo que siente la persona que sufre, al ponernos en su lugar” (Smith 1759: 49-50).

Por eso, somos egoístas y, a la vez, compasivos, es decir, complejos. Y por eso, Smith estudia el egoísmo y también la compasión o la empatía, aunque advierte que no siempre tenemos esos sentimientos ni sabemos por qué surgen. “...esto no es universalmente válido ni rige para todas las pasiones. Algunas de ellas no generan identificación alguna, y antes de que detectemos lo que las ha promovido nos suscitan disgusto y rechazo...No sabemos cómo ha sido provocado, no podemos situarnos en su lugar ni concebir nada parecido a las pasiones que dicha provocación desata”. (Ibid: 52-53). Es decir, la capacidad de ponernos en el lugar de los demás es una de las cuestiones a las que Smith le dedica una gran atención porque si no somos capaces de ponernos en el lugar del otro, no seremos capaces ni de entendernos ni de entenderle. Más concretamente, "La compasión no emerge tanto de la observación de la pasión como de la circunstancia que la promueve (...) La compasión del espectador debe provenir totalmente de la consideración de lo que él mismo sentiría si fuese reducido 
a la misma infeliz posición y al mismo tiempo pudiese, lo que quizá es imposible, ponderarla con la razón y el juicio que ahora posee”. (Ibid: 52).

Sin embargo, sí reconoce con claridad que cuando dos personas son capaces de sentir compasión, aunque no se sepa por qué, poniéndose cada una en el lugar de la otra, entonces son capaces de entenderse y relaciona el entendimiento con la capacidad previa de sentir. "Cuando las pasiones originales de la persona principalmente afectada están en perfecta consonancia con las emociones simpatizadoras del espectador, necesariamente le parecen a este último justas y apropiadas, y en armonía con sus objetos respectivos; en cambio, cuando comprueba, poniéndose en el caso, que no coinciden con lo que siente, entonces necesariamente le parecerán injustas e inapropiadas, y en contradicción con las causas que las excitan... En consecuencia, aprobar las pasiones de otro como adecuadas a sus objetos es lo mismo que observar que nos identificamos completamente con ellas, y no aprobarlas es lo mismo que observar que no simpatizamos totalmente con ellas...Por el contrario, la persona que...no siente la emoción que siento yo, o no la siente en la misma proporción, no podrá evitar desaprobar mis sentimientos debido a la discordancia de éstos con los suyos... Aprobar las opiniones de otra persona es adoptar dichas opiniones, y adoptarlas es aprobarlas. Si los mismos argumentos que usted encuentra convincentes me convencen a mí también, necesariamente yo aprobaré su convicción; en caso contrario, necesariamente la desaprobaré: no es posible concebir una cosa sin la otra...Cada facultad de un ser humano es la medida con la cual juzga la misma facultad en otro... No tengo ni puedo tener otra forma de juzgarlos” (Ibid: 62-66). (La negrita es mía).

Es muy interesante ver que estas reflexiones intuitivas, basadas en la observación y hechas hace más de dos siglos, coinciden básicamente, con lo que actualmente se va conociendo sobre el comportamiento humano. Por ejemplo, resulta sorprendente la coincidencia entre Maturana y lo que plantea más arriba Adam Smith. Así, "El <emocionar> que vivimos determina en cada instante lo que podemos ver, admitir, escoger o hacer en ese instante. El razonar es algo básicamente diferente... Todo argumento racional, todo sistema de pensamiento racional, se funda en premisas fundamentales no racionales adoptadas a priori desde las preferencias, deseos, miedos, aspiraciones...de quien lo propone. En estas circunstancias, para que un interlocutor acepte un argumento nuestro supuestamente racional entendiendo lo que dice y lo haga sintiéndose obligado por él, debe aceptar las premisas básicas a priori que lo fundamentan y sentirse comprometido por ellas” (Maturana 2005: 10-11). (La negrita es mía).

El problema, siguiendo a Maturana, es que los seres humanos nos creemos seres racionales pero somos, básicamente, seres emocionales siendo este dejar de lado lo emocional lo que nos impide entendernos. "Como creemos que los conflictos humanos surgen de conductas irracionales, queremos resolverlos desde la razón, pero la razón no resuelve los conflictos humanos... los errores en un razonar son triviales y se resuelven revisando el desarrollo del argumento sin mucha dificultad emocional. Si 
en una conversación surge un conflicto emocional, las discrepancias que allí aparecen se tornan amenazantes, y generan grandes enojos, ya que ponen en riesgo los fundamentos conceptuales, pensados o no pensados, del vivir y convivir de los participantes. Por eso, cada vez que nos encontramos ante una pretendida discrepancia racional que da origen a enojos, sabemos que las personas que discuten lo hacen, sin darse cuenta o con malicia, desde sistemas racionales que se fundan en premisas a priori diferentes, de modo que ninguna de las personas discrepantes comete un error racional... Los conflictos humanos jamás se resuelven desde la razón, y en los casos en que parece haber sucedido así, lo que sin duda ha ocurrido es que una u otra de las partes involucradas en el conflicto ha cambiado su <emocionar>, ya sea de manera consciente o inconsciente" (Ibid: 11-12). (La negrita es mía). En definitiva, "Ningún argumento racional es aceptable para quien no acepta, sea de modo consciente o inconsciente, las premisas básicas que le dan validez, (lo que requiere) una completa coincidencia emocional con la naturaleza de la invitación, precisamente porque su validez en la acción es emocional y no racional” (Ibid: 13-14). En una línea similar se mueve Damasio para quien no hay razones sin emociones previas.

Por su parte, De Waal llega a conclusiones muy parecidas pero basándose en su trabajo con diferentes tipos de monos y defiende que "Nuestra mejor esperanza de éxito se basa en las emociones morales, porque las emociones son desobedientes. En principio, la empatía puede imponerse a cualquier regla sobre cómo tratar a los miembros de grupos ajenos...Las emociones triunfan sobre las reglas. Por eso, al hablar de modelos de conducta moral hablamos de nuestros corazones y no de nuestros cerebros...A la hora de resolver dilemas morales confiamos más en lo que sentimos que en lo que pensamos” (De Waal 2007: 226) reconociendo que somos “monos bipolares" y que "La visión que nos retrata como egoístas y mezquinos, con una moralidad ilusoria, debe revisarse. Si somos esencialmente antropoides (...) o al menos descendientes de antropoides, entonces nacemos con una gama de tendencias, desde las más básicas hasta las más nobles. Lejos de ser un producto de la imaginación, nuestra moralidad es el resultado del mismo proceso de selección que conformó nuestro lado competitivo y agresivo" (Ibid: 250).

Pero da igual lo que escribió Adam Smith, lo que sabemos sobre el ser humano e incluso nuestra práctica cotidiana, oficialmente para la economía académica las personas somos, básicamente, sólo agentes racionales egoístas sin capacidad para cooperar o para tener comportamientos cooperativos.

Y lo peor es que nos llegamos a convencer de que somos así al concederle más autoridad a lo que nos dicen los Manuales de economía que a nuestra propia práctica. Mi experiencia al discutir estas cuestiones con los estudiantes choca, año tras año, con el convencimiento (la creencia aprendida) de que todos somos egoístas por naturaleza y de que el hombre es un lobo para el hombre. Es sorprendente constatar que leen directamente 
a De Waal en mis cursos y “aprenden” que el lobo es uno de los animales más cooperativos, que los primates aprenden a cooperar, que los sentimientos cuentan a la hora de tomar decisiones,... etc., pero estas lecturas y estos “aprendizajes” no llegan a formar parte de sus argumentos (de sus hábitos de pensamiento) lo que refleja el poder de lo "aprendido" de manera repetitiva frente a lo que ellos mismos leen de manera argumentada. Tardan mucho en ‘oír', como dice José Luis Sampedro, por llevar muchos años sometidos al machaqueo del mismo martillo.

\section{Competencia, interés individual, reglas y justicia}

Al contrario de lo que se enseña y se repite continuamente por parte de los poderosos y los ignorantes, con frecuencia de manera interesada, Adam Smith no era precisamente un obseso de los supuestos mercados libres, es decir, sin reglas, sino todo lo contrario pues consideraba necesarias esas reglas para proteger a los ciudadanos de los abusos de los poderosos. Por eso defiende el interés individual siempre que no vaya contra los demás, es decir, contra la comunidad y acate las leyes de la justicia.

Por lo que podemos deducir de sus textos, Smith conocía bien qué eran los mercados, cómo funcionaban así como el abuso habitual que practicaban los empresarios poderosos. De hecho, Smith tenía una gran prevención hacia los empresarios que vivían de los beneficios del capital, es decir, los comerciantes y los fabricantes, si bien los consideraba más inteligentes, “acuidad mental” dice él, que los terratenientes que viven de la renta de la tierra a los que califica de indolentes. Así, en "La riqueza de las naciones" escrita en 1776, en el apartado de Conclusiones del Libro I, afirmaba de manera contundente "Los intereses de quienes trafican en ciertos ramos del comercio o de las manufacturas (...) no sólo son diferentes sino por completo opuestos al bien público. El interés de los empresarios siempre es ensanchar el mercado pero estrechar la competencia. La extensión del mercado suele coincidir con el interés general, pero el reducir la competencia siempre va en contra de dicho interés, y sólo puede servir para que los empresarios, al elevar sus beneficios por encima de lo que naturalmente serían, impongan en provecho propio un impuesto absurdo sobre el resto de sus compatriotas. Cualquier propuesta de una nueva ley o regulación comercial que venga de esta categoría de personas (los empresarios) debe siempre ser considerada con la máxima precaución, y nunca debe ser adoptada sino después de una investigación prolongada y cuidadosa, desarrollada no sólo con la atención más escrupulosa, sino también con el máximo recelo. Porque provendrá de una clase de hombres cuyos intereses nunca coinciden exactamente con los de la sociedad, que tienen generalmente un interés en engañar e incluso oprimir a la comunidad, y que de hecho la han engañado y oprimido en numerosas oportunidades”' (Smith 1776: 343-344). (La negrita es mía). De manera similar se expresa en una carta a Rochefoucauld afirmando “....aquellos que tienen el mayor interés en defraudar y en imponerse al público son los que con frecuencia dictan la regulación del comercio”. (Carta 248 dirigida a Rochefoucauld en 1785, refiriéndose a Gran Bretaña). 
Y da ejemplos de cómo los empresarios controlan los salarios y de sus quejas continuas si suben esos salarios así como, a la vez, del silencio total que muestran ante el crecimiento de los beneficios, algo de una actualidad innegable pues, sea cual sea el origen de los problemas económicos, sabemos que gobiernos y empresarios siempre imponen la misma solución, es decir, la bajada de los salarios. "No tenemos leyes del Parlamento contra las uniones que pretenden rebajar el precio del trabajo; pero hay muchas contra las uniones que aspiran a subirlo. Los patronos están siempre y en todo lugar en una especie de acuerdo, tácito pero constante y uniforme, para no elevar los salarios sobre la tasa que existe en cada momento. Violar este concierto es en todo lugar el acto más impopular, y expone al patrono que lo comete al reproche entre sus vecinos y sus pares. Es verdad que rara vez oímos hablar de este acuerdo, porque es el estado de cosas usual, y uno podría decir natural, del que nadie oye hablar jamás” (Ibid: 111) y también "Nuestros comerciantes e industriales se quejan mucho de los efectos perjudiciales de los altos salarios, porque suben los precios y por ello restringen la venta de sus bienes en el país y en el exterior. Nada dicen de los efectos dañinos de los beneficios elevados. Guardan silencio sobre las consecuencias perniciosas de sus propias ganancias.” (Ibid: 151)

Por eso escribe sobre la necesidad de las reglas basadas en el objetivo de la justicia. "La sociedad puede mantenerse sin beneficencia, aunque no es la situación más confortable; pero si prevalece la injusticia, su destrucción será completa (...) La beneficencia....es el adorno que embellece el edificio....La justicia, en cambio, es el pilar fundamental en el que se apoya todo el edificio. Si desaparece, entonces el inmenso tejido de la sociedad humana...en un momento será pulverizada en átomos” (Smith, 1759, 1997, 182-186). No se está refiriendo, obviamente, a los tribunales de justicia sino a la existencia de una economía que incorpore prácticas justas e, implícitamente, orientada al bien común.

"En la carrera hacia la riqueza...él podrá correr con todas sus fuerzas... Pero si empuja o derriba a alguno, la indulgencia de los espectadores se esfuma. Se trata de una violación del juego limpio, que no podrán aceptar”. (Ibid: 182). Dicho de otra manera, el hombre prudente sólo mejora lo propio cuando no afecta injustamente a los demás, idea sobre la que vuelve con frecuencia, tanto en la Teoría de los sentimientos morales como en la La riqueza de las naciones. "Toda persona, en tanto no viole las leyes de la justicia, queda en perfecta libertad para perseguir su propio interés a su manera y para conducir a su trabajo y su capital hacia la competencia con toda persona o clase de personas". (Smith, 1776, 660). Prueba de que esta cuestión no es algo trivial o de escasa importancia para él, además de lo que hemos visto, es que la incorpora de manera muy clara en sus clases (Lecciones sobre Jurisprudencia) que imparte durante el Curso 1762-63, "Las leyes y el gobierno se pueden considerar, en todos los casos, como un arreglo de los ricos para oprimir a los pobres y preservar en su favor la desigualdad de bienes.....”. (Smith 1995: 246). 
Esta última cita es, sorprendentemente, casi una copia exacta de lo que expresaba Tomás Moro en 1516, “...todas esas repúblicas que hoy florecen por ahí, no se me antojan otra cosa, séame Dios propicio, que una especie de conspiración de los ricos que tratan de sus intereses bajo el nombre y título de república. Y discurren e inventan todos los modos y artes para retener lo que apañaron con malas artes... y para adquirirlo al más bajo costo con el trabajo y fatigas de todos los pobres y para aprovecharse de éstos. Estas maquinaciones, tan pronto como los ricos han decretado que se observen en nombre del pueblo, pasan ya a ser leyes. ...estos hombres funestísimos, lo que sería suficiente para todos, se lo reparten todo entre ellos con insaciable codicia”. (Moro 2011: 196). Tanto Moro como Smith sabían bien de quién estaban hablando y qué comportamientos tenían, conocían a aquellos empresarios, hablan de las mismas personas que, como ocurre actualmente, toman decisiones para saquear lo público, para recortar derechos sociales y personales, supuestamente en nombre del interés público y de la democracia pero, realmente, para beneficiar a unos pocos.

Y entonces, como señala Casassas (2013) ¿Qué ocurre con la famosa metáfora de la mano invisible? "Cierto es que los intercambios descentralizados -los mercados- guiados por nuestros respectivos <sentidos comunes $>$ relativos a las mejores maneras de mejorar nuestras condiciones de vida pueden llevarnos a estadios sociales y civilizatorios de mayor libertad, felicidad y bienestar......para que ello sea así es necesario garantizar que esos intercambios descentralizados que se dan en los mercados sean realmente libres. Y para ello es preciso...que las instituciones políticas intervengan radicalmente para deshacer vínculos de dependencia y relaciones de poder enraizados en privilegios de clase, en relaciones de clase" (Casassas 2013: 38). Nunca se insistirá bastante en la necesidad de hacer una lectura honesta de Smith.

\section{Comunidad, naturaleza y conciencia}

Quizás uno de los aspectos más llamativos consiste en cómo consideraba Smith la relación del hombre con la naturaleza a cuya comunidad pertenece. Cada uno puede sacar sus propias conclusiones pero la expresión que él hace de esta relación, ciertamente de manera breve, es muy sugestiva y mucho más viendo esto en perspectiva. "El hombre, según los estoicos, debe considerarse a sí mismo no como algo separado y distinto, sino como un ciudadano del mundo, miembro de la vasta comunidad de la naturaleza. En interés de esta amplia comunidad él debe estar constantemente dispuesto a sacrificar su reducido interés personal. Cualquier cosa que le concierna no debe afectarlo más que cualquier otra cosa que concierna a otra parte igualmente importante de ese inmenso sistema” (Smith 1759: 265). Pero ¿Cómo sabe el hombre esto o cómo puede entender el hombre su propia condición? A través de la conciencia. “¿Qué es lo que impele a los generosos siempre y a los mezquinos muchas veces a sacrificar sus propios intereses a los intereses más importantes de otros? No es el apagado poder del humanitarismo, no es el tenue destello de la benevolencia que la naturaleza ha encendido en el corazón humano lo que es así capaz de contrarrestar 
los impulsos más poderosos del amor propio. Lo que se ejercita en tales ocasiones es un poder más fuerte, una motivación más enérgica. Es la razón, el principio, la conciencia, el habitante del pecho, el hombre interior, el ilustre juez y árbitro de nuestra conducta” (Ibid: 260). Conciencia que nos remite al tema de la compasión que, en definitiva, significa tener conciencia de uno mismo, de los demás y de la naturaleza, es decir, de la comunidad, saber quién es uno, saber dónde vive, formar parte de esa comunidad.

Es más, no deja de tener una gran relevancia el hecho de que Smith mencione que, inicialmente, el crimen más importante, el más castigado, no era vivido como el crimen contra las personas sino el crimen contra la comunidad. “...los crímenes que parecen más atroces para los individuos no fueron los primeros en estar sujetos a lo que se llama propiamente castigo...sino los que golpeaban inmediatamente el bienestar de la comunidad. Son dos, la traición y la cobardía...”. (Smith, 1995, 247). Entiendo que estas citas son más que relevantes para animar a los lectores a profundizar en la lectura original de este autor pues encontrarán reflexiones, sugerencias y juicios muy lúcidos sobre el ser humano, la ética y el poder, entre otros temas.

Sin embargo lo que se transmite es todo lo contrario debido a la malinterpretación deliberada y sesgada de Smith. "La mala interpretación de la completa actitud de Smith respecto a la motivación y a los mercados, y el abandono de sus analistas de los sentimientos y del comportamiento, se ajusta muy bien al distanciamiento de la economía y de la ética que se ha producido en el desarrollo de la economía moderna (...) El apoyo que los seguidores y los partidarios del comportamiento egoísta han buscado en Adam Smith es difícil de encontrar en una lectura más profunda y menos segada de su obra (...) es precisamente la reducción de la amplia visión smitheana de los seres humanos lo que puede considerarse como una de las mayores deficiencias de la teoría económica contemporánea. Este empobrecimiento se encuentra íntimamente relacionado con el distanciamiento de la economía y de la ética.” (Sen 1989: 44-45). (La negrita es mía). (Véase también Casassas, 2010).

Termino con una referencia a la crítica que hace Smith a la desigualdad entre ricos y pobres y de la ausencia de comunidad que ello implica. "Cuando hay grandes propiedades hay grandes desigualdades. Por cada hombre muy rico debe haber al menos quinientos pobres, y la opulencia de unos pocos supone la indigencia de muchos. La abundancia de los ricos aviva la indignación de los pobres, que son conducidos por la necesidad y alentados por la envidia a atropellar sus posesiones” (Smith 1776: 675)

\section{Algunas pinceladas sobre Marx y el ser humano consciente, no enajenado}

De igual manera que Smith se ha reducido a unas cuantas etiquetas que se repiten como si fueran verdad, con Marx ha pasado algo parecido. En este capítulo me referiré a uno de sus trabajos menos conocido entre los 
economistas, se trata de los Manuscritos económico-filosóficos. Me interesa destacar especialmente su protesta por la deshumanización del ser humano, su enajenación, entendida por él como una "existencia sin esencia”, al ser considerado y transformado por la economía política y por el capitalismo en mercancía (trabajo sin sentido) a la que se le crean continuamente necesidades artificiales ignorando la auténtica esencia espiritual de ese ser humano.

El punto de partida de la crítica de Marx es que “...el trabajador desciende al nivel de mercancía y de una mercancía miserable; que la miseria del trabajador aumenta con la fuerza y el volumen de su producción” (Marx 1975: 103). La miseria a la que se refiere no es sólo material sino también mental y psíquica, "El trabajador se convierte en una mercancía más barata cuantos más bienes crea. La devaluación del mundo humano aumenta en relación directa con el incremento de valor del mundo de las cosas...el trabajador se relaciona con el producto de su trabajo como un objeto ajeno... cuanto más se gasta el trabajador en su trabajo más poderoso se vuelve el mundo de los objetos que crea frente a sí mismo, más pobre se vuelve su vida interior y menos se pertenece a sí mismo. Sucede lo mismo que con la religión. Cuanto más de sí mismo atribuya el hombre a Dios, menos le queda para sí. El trabajador pone su vida en el objeto y su vida no le pertenece ya a él sino al objeto.” (Marx 1975: 105-106. La negrita es cursiva en el original).

Este trabajo convertido en mercancía es completamente diferente del trabajo no mercancía en el que el trabajador "se sigue perteneciendo a sí mismo”, trabaja para él y desde él. Evidentemente hay trabajos mercancía en los que un trabajador puede disfrutar sin perderse a sí mismo pero no es, obviamente, a este trabajo minoritario al que se está refiriendo Marx. Tampoco es cierto que todo trabajo no mercancía permita que el trabajador se realice en el trabajo ni se afirme a sí mismo, pero entiendo que esto no invalida la reflexión genérica reflexión de Marx sobre cómo se siente el trabajador mercancía. “¿Qué constituye la enajenación del trabajo? Primero, que el trabajo es externo al trabajador, que no es parte de su naturaleza; y que en consecuencia, no se realiza en su trabajo sino que se niega, experimenta una sensación de malestar más que de bienestar, no desarrolla libremente sus energías mentales y físicas sino que se encuentra físicamente exhausto y mentalmente abatido... (el trabajo) no es la satisfacción de una necesidad, sino sólo un medio para satisfacer otras necesidades” (Ibid: 109. La negrita es cursiva en el original).

De aquí pasa Marx a una reflexión sobre el hombre, su propia naturaleza, y la relación más amplia con la naturaleza, medio ambiente, en el que vive y del que depende, de manera parecida a la reflexión de Smith sobre los estoicos. "La naturaleza es el cuerpo inorgánico del hombre; es decir, la naturaleza excluyendo al cuerpo humano mismo. Decir que el hombre vive de la naturaleza significa que la naturaleza es su cuerpo, con el cual debe permanecer en continuo intercambio para no morir. La afirmación de que la vida física y mental del hombre y la naturaleza son interdependientes signi- 
fica simplemente que la naturaleza es interdependiente consigo misma, puesto que el hombre es parte de la naturaleza” (Ibid: 110). El problema reside en la enajenación del trabajo y sus implicaciones.

“Como el trabajo enajenado: 1) enajena a la naturaleza del hombre; y 2) enajena al hombre de sí mismo, de su propia función activa, de su actividad vital, así lo enajena de la especie... Porque el trabajo, la actividad vital, la vida productiva, aparecen ahora ante el hombre únicamente como medios para la satisfacción de una necesidad, la necesidad de mantener su existencia física. La vida productiva es, sin embargo, vida de la especie. Es la vida que crea vida. En el tipo de actividad vital reside todo el carácter de una especie... y la actividad libre, consciente, es el carácter de los seres humanos como especie... En general, la afirmación de que el hombre se enajena de su vida como especie significa que cada hombre está enajenado en relación con los otros y que cada uno de los otros está, a su vez, enajenado de la vida humana” (Ibid: 110-113) (La negrita es cursiva en el original).

Pero frente a este ser libre y consciente, "La propiedad privada nos ha hecho tan estúpidos y parciales que un objeto es sólo 7 cuando lo poseemos, cuando existe para nosotros como capital o cuando es directamente comido, bebido, usado como vestido, habitado, etc., es decir, utilizado de alguna manera (...) Así todos los sentidos físicos e intelectuales han sido sustituidos por la simple enajenación de todos estos sentidos: el sentido del tener. El ser humano tenía que ser reducido a esta absoluta pobreza para poder dar origen a toda su riqueza interior" (Ibid: 140) (La negrita es cursiva en el original). Esta distinción entre el tener y el ser daría título a uno de los libros de Fromm, 'Del tener al ser'. En cualquier caso, me parece muy relevante la reflexión que hace Marx puesto que expresa el proceso de empobrecimiento intelectual y psíquico del ser humano al sustituir todos los sentidos (el hecho de ser) por el deseo de tener como objetivo en la vida, convirtiendo al hombre, apenas ya ser humano, en un puro consumidor.

Como escribió con acierto Fromm, respondiendo a su pregunta ¿Qué clase de hombre requiere esta sociedad para funcionar bien? : «Hombres que cooperen dócilmente en grupos numerosos, que deseen consumir más y más, y cuyos gustos estén estandarizados y puedan ser fácilmente influidos y anticipados. Hombres que se sientan libres e independientes y que estén dispuestos a ser mandados, a encajar sin roces en la máquina social. Que puedan ser guiados sin fuerza, conducidos sin líderes, impulsados sin meta, salvo la de continuar en movimiento, de funcionar, de avanzar. Es el hombre enajenado, en el sentido de que sus acciones y sus propias fuer-zas se han convertido en algo ajeno, que ya no le pertenecen» (Fromm 1981: 1112). Y este tipo de personas es el que mayoritariamente mantiene, consciente o inconscientemente, esta sociedad viviendo como si fuera normal, en el sentido de razonable, lo que no es nada más que una patología, una anormalidad en el sentido de que no tiene nada de normal vivir como un hombreconsumidor-trabajador enajenado. 
Volviendo a Fromm, que escribió una excelente introducción a la edición que manejo de los Manuscritos económico-filosóficos, y que da nombre al conjunto del libro titulado Marx y su concepto del hombre, "El fin de Marx era la emancipación espiritual del hombre, su liberación de las cadenas del determinismo económico, su restitución a su totalidad humana, el encuentro de una unidad y armonía entre sus semejantes y con la naturaleza (...) Es precisamente la ceguera del pensamiento consciente del hombre lo que le impide tener conciencia de sus verdaderas necesidades humanas y de los ideales arraigados en ellas. Sólo si la conciencia falsa se transforma en conciencia verdadera, es decir, sólo si tenemos conciencia de la realidad, en vez de deformarla mediante racionalizaciones y ficciones, podemos cobrar conciencia también de nuestras necesidades humanas reales y verdaderas” (Fromm 1975: 15-33). ¿Y cómo puede el hombre transformar esa conciencia? Haciéndose 'productivo' en el sentido de relacionarse con el mundo para entenderlo y entenderse. "Para Spinoza, Goethe, Hegel y Marx, el hombre vive sólo en tanto que es productivo, en tanto que capta al mundo que está fuera de él en el acto de expresar sus propias capacidades humanas específicas y de captar al mundo con estas capacidades (...) En este proceso productivo, el hombre realiza su propia esencia, vuelve a su propia esencia, que en el lenguaje teológico no es otra cosa que su vuelta a Dios.” (Ibid: 41).

Me parece muy interesante señalar que esa idea del hombre productivo (vivo), que se pertenece a sí mismo diría Marx, frente al hombre pasivo (el hombre mercancía enajenado) se encuentra también en Smith, al hablar del hombre consciente, como vimos más arriba y también al referirse al hombre como el 'agente' (protagonista de su propia vida) que se opone al 'paciente', al hombre pasivo, distinción a la que Sen daría una gran relevancia en su noción de Desarrollo como libertad, es decir, como creatividad esencial del ser humano (Sen, 2001). ¿Qué es lo que ha pasado para que, por lo que yo conozco, estos planteamientos y reflexiones de Smith y de Marx sean casi desconocidos? En mi opinión, que no se les lee y se repiten y mantienen las etiquetas con las que se les identifica y se les empobrece.

Se puede afirmar que en ambos casos asistimos a una cuestión de malinterpretación deliberada y malintencionada o, si se prefiere, a una falsificación en toda regla de lo que se ha considerado que era el núcleo de sus escritos, algo bastante habitual en Ciencias Sociales y además fácil de constatar a poco que uno se tome la molestia de leer los textos originales y contrastarlos con las versiones que se divulgan de ellos. El problema es que en las Facultades de economía se suelen leer pocos textos originales y se divulgan muchos tópicos-etiquetas, de ahí que la malinterpretación, con frecuencia basada en la ignorancia, afecte a muchos autores. Naredo, refiriéndose entre otros a Pareto y Cournot señala que “...se ha tomado de su pensamiento aquello que venía bien para afianzar o ampliar el edificio de la ciencia económica establecida, haciendo caso omiso de otras consideraciones suyas que trascendían dicho campo o evidenciaban lo limitado del mismo" (Naredo 1987: 323), lo que muestra la práctica habitual de la malinterpretación y de una lectura sesgada en toda regla. 
En este sentido, el primer apartado de la introducción escrita por Fromm se titula 'La falsificación de las concepciones en Marx’ y empieza así "Una de las ironías peculiares de la historia es que no haya límites para el malentendimiento y la deformación de las teorías, aun en una época donde hay acceso ilimitado a la fuentes” (Fromm 1962: 13), poniendo de ejemplo a lo que ha ocurrido con Marx. Para Fromm, Marx tiene un componente espiritual o místico que es totalmente incompatible con la versión materialista que se ha difundido de él. De hecho, señala la “ironía existente en el hecho de que la descripción que se hace del propósito y de su visión del socialismo corresponda casi exactamente a la realidad de la sociedad capitalista occidental de nuestros días”. (Ibid: 15).

\section{Notas finales: hay algo de locura en esta cultura y en las personas... pero hay luz}

Sabemos que es muy difícil cambiar una situación de la que no somos conscientes. El aprendizaje recibido nos impide entender y ver con claridad lo que debería ser cambiado para vivir como seres humanos. A pesar de que hay muchas y muy lúcidas reflexiones y diagnósticos sobre la economía en la que vivimos y cómo la vivimos nos va a costar mucho “darnos cuenta” de lo que ocurre.

Polanyi hacía un diagnóstico espléndido a mediados del siglo pasado que apenas ha sido escuchado. "Hemos sido reducidos a la impotencia por la herencia de una economía de mercado que transmite concepciones simplistas sobre la función y el papel del sistema económico en la sociedad (...) Para superar tales doctrinas, que nublan nuestra mente y nuestro espíritu...es necesario reformar nuestra conciencia (...) El hombre es un ser social (y) jamás fue tan egoísta como querría esta teoría...sus móviles económicos jamás han constituido su único incentivo para trabajar (...) A pesar de ello, nos ocupamos no de las motivaciones efectivas sino de las motivaciones supuestas, no de la psicología sino de la ideología de la actividad económica (...) Las concepciones de la naturaleza humana se basan en la última y no en la primera”. (Polanyi 1947: 52).

Psiquiatras como Lowen han expresado, más recientemente y con enorme claridad, la inversión de valores en la que nos encontramos, calificando de narcisismo lo que estamos viviendo y aunque no ha recibido mucha atención por parte de los economistas “...se puede entender el narcisismo como una pérdida de valores humanos -ausencia de interés por el entorno, por la calidad de vida, por las demás personas -. Una sociedad que sacrifica su medio natural para obtener dinero y poder no tiene sensibilidad para las necesidades humanas. La proliferación de cosas materiales se convierte en la medida del progreso vital... Hay algo de locura en una pauta de conducta que sitúa el logro del éxito por encima de amar y ser amado. Hay algo de locura en una persona que no conecta con la realidad de su propio ser -su cuerpo y los sentimientos que derivan de éste-. Y hay también algo 
de locura en una cultura que contamina el aire, el agua y la tierra en aras de alcanzar un nivel de vida <más alto>” (Lowen 2009: 11-13).

Cada vez podemos ver con más claridad y cada vez es, también, más fuerte la manipulación y la confusión. La esperanza, dice Morin, está en lo inesperado, en hacer lo que tiene sentido para uno aunque parezca que se hace poco. Lo inesperado es, por otro lado, el propio ser humano, uno mismo, como venía a decir De Waal más arriba, algo que es muy importante tener claro sobre todo en estos largos tiempos de oscuridad. "Los tiempos de oscuridad...no sólo no son nuevos sino que no son una rareza en la historia...aún en los tiempos más oscuros tenemos el derecho a esperar cierta iluminación y que dicha iluminación puede provenir menos de las teorías y conceptos que de la luz incierta, titilante y a menudo débil que algunos hombres y mujeres reflejarán en sus trabajos y sus vidas bajo casi cualquier circunstancia y sobre la época que les tocó vivir en la tierra...Ojos tan acostumbrados a la oscuridad como los nuestros apenas podrán distinguir si su luz fue la luz de una vela o la de un sol brillante” (Arendt, 1955, 11). Pero es luz. 


\section{Bibliografía}

Aguilera, F. (2010), “La economía como sistema abierto: de la disociación a la integración”, en Revista Sustentabilidad(es), № 2.

Idem, (coordinador), (2013), “Para la rehumanización de la economía”. Mediterráneo económico n² 23. Cajamar. Almería.

Arendt, H. (1955), Hombres en tiempos de oscuridad. Gedisa. Serie Esquinas. Barcelona, 1990.

Benedict, R. (1967), El hombre y la cultura. Editorial Sudamericana, Buenos Aires.

Casassas, D. (2010), La ciudad en llamas: la vigencia del republicanismo comercial de Adam Smith. Montesinos, Barcelona.

Idem, (2013), “Comercio y emancipación social en el republicanismo de Adam Smith: Una lectura contemporánea”, 31-52 en Aguilera 2013.

Damasio, A. (2006), El error de Descartes. Crítica, Barcelona.

De Waal, F. (2007), El mono que llevamos dentro. Metatemas Tusquets, Barcelona.

Idem, (2011), La edad de la empatía. Fábula. Tusquets, Barcelona.

Fernández Liria, A. (2013), “Economía y psico(pato)logía, 125-137 en Aguilera (2013).

Fromm, E. (1962), Marx y su concepto del hombre. Fondo de Cultura Económica, México. 1975.

Idem, (1963), La condición humana actual. Paidós, Barcelona. 1981.

Idem, (1994), La patología de la normalidad. Paidós, Barcelona.

Galbraith, J. K. (2004), La economía del fraude inocente. La verdad de nuestro tiempo. Crítica, Barcelona.

Galeano, E. (1998), Patas arriba. La escuela del mundo al revés. Siglo XXI, Madrid.

Kapp, K. W. (1950), The Social Costs of Private Enterprise. Cambridge, Mass: Harvard University Press. (Existe versión en español, Los costes sociales de la empresa privada. Oikos-Tau. Barcelona, 1966).

Kapp, K. W. (1968), “En defensa de la economía institucional”, 219-235 en Aguilera F. (Coordinador). Economía de los recursos naturales: un enfoque 
institucional. Fundación Argentaria-Visor Distribuciones, Madrid. 1995.

Leontief, W. (1982), “Economía académica”, en Archipiélago n 33, 28-33, 1998.

Lowen, A. (2000), El narcisismo. Paidos, Barcelona.

Marglin, S. (2008), The Dismal Science. How Thinking Like an Economist Undermines Community. Harvard University Press, Cambridge.

Marx, K. (1844), Manuscritos económico-filosóficos. Fondo de Cultura Económica, Mexico. 1975.

Maslow, A. (1982), La personalidad creadora. Kairós, Barcelona.

Maturana, H. (2005), "Prefacio" en Elizalde A. (2005), Desarrollo humano y ética de la sostenibilidad. PPC, Madrid

Mishan, E. J. (1971), Los costes del desarrollo económico. OikosTau.,Barcelona.

Morin, E. (1993), “El desafío de la globalidad”. Archipiélago n 16, 66-72.

Idem, (2001), Los siete saberes necesarios para la educación del futuro. Paidos, Barcelona.

Morin, E. (2011), La Vía. Para el futuro de la humanidad. Paidós, Barcelona.

Moro, T. (1516), Utopía. Akal, Madrid. 2011. (Edición de Emilio García Estébanez).

Naredo, J. (1987), La economía en evolución. Siglo XXI, Madrid.

Polanyi, K. (1947), Nuestra obsoleta mentalidad de mercado. Aguilera 2013.

Sampedro, J. L. (1961), El río que nos lleva. Debolsillo, Barcelona. 2013.

Schirrmacher, F. (2014), Ego. Las trampas del juego capitalista. Ariel, Barcelona

Sen, A. (1989), Sobre ética y economía. Alianza Editorial, Madrid.

Idem, (2001), Desarrollo y libertad. Planeta, Barcelona. 2000

Smith, A. (1759), Teoría de los sentimientos morales. Alianza editorial., Madrid. 1997. 
Polis, Revista Latinoamericana, Volumen 14, $N^{\circ}$ 41, 2015

Idem, (1776), La riqueza de las naciones. Alianza editorial, Madrid. 1994.

Idem, (1995), Lecciones sobre Jurisprudencia. Curso 1762-63. Biblioteca Comares de Ciencia Jurídica, Granada.

Recibido: 24.07.2015

Aceptado: 15.08.2015 